\title{
Communication
}

\section{Cellulases in Ionic Liquids-The Long Term Stability of Aspergillus sp. Cellulase}

\section{Nele Ilmberger, Julia Pottkämper and Wolfgang R. Streit *}

Microbiology \& Biotechnology, University of Hamburg, Ohnhorststrasse 18, 22609 Hamburg, Germany; E-Mails: Nele.Ilmberger@uni-hamburg.de (N.I.); ju.pottkaemper@gmx.de (J.P.)

* Author to whom correspondence should be addressed; E-Mail: Wolfgang.Streit@uni-hamburg.de; Tel.: +49-40-42816-463; Fax: +49+40-42816-459.

Received: 12 April 2013; in revised form: 27 May 2013 / Accepted: 4 June 2013 /

Published: 13 June 2013

\begin{abstract}
It is a well known fact that some ionic liquids (ILs) have the potential to dissolve crystalline, water-insoluble cellulose that could be used as a source of glucose and subsequently derived molecules. Nevertheless, in the presence of high IL concentrations, cellulase activity and, even more so, cellulase stability are still challenging difficulties that need to be overcome. Therefore four fungal cellulase preparations were assayed in the presence of $30 \%(v / v)$ of five different ILs. Thereby the cellulase from Aspergillus sp. (Sigma-Aldrich) was not only remarkably active (up to $28 \mathrm{U} / \mathrm{mg}$ in $30 \%(v / v)$ IL ([BMMIM]Cl)), but furthermore stayed active during several weeks in the presence of $60 \%$ $(v / v)$ IL (up to $50 \%$ relative activity after 9 weeks).
\end{abstract}

Keywords: ionic liquid; cellulase; Aspergillus

\section{Introduction}

The enzymatic conversion of cellulose into glucose, and subsequently biofuels, could provide a renewable and sustainable energy source. A major difficulty that needs to be mastered in this degradation process is the insolubility of crystalline cellulose in water. Several ionic liquids (ILs) have been shown to dissolve water-insoluble cellulose and/or wood. Among these is 1-butyl-3methylimidazolium chloride ([BMIM]Cl) [1,2]. Hence, ILs could be used as a reaction medium for the enzymatic hydrolysis of cellulose, if cellulases were shown to be active and stable in the presence of high IL concentrations. To date only a limited number of cellulases have been described as being 
active in the presence of ILs. The majority of cellulases, including a preparation from Trichoderma reesei, appear to be inactive in the presence of IL concentrations above 20\% (v/v) [3,4]. In contrast, some thermostable cellulases have shown high activity in the presence of about $30 \%(v / v)$ IL $[5,6]$. Nevertheless, the stability of cellulolytic activity in the presence of high IL concentrations during relevant time periods remains to be demonstrated. Fungal enzymes are often more stable due to glycosylation, and have been shown to be persistent in the presence of proteases, high temperatures, and surfactants [7-9].

\section{Results and Discussion}

The cellulases derived from Trichoderma reesei and $T$. viride were almost inactive in the presence of $30 \%(v / v)$ of all tested ILs (Figure 1), whereby 30\% $(v / v)$ IL was chosen, as it turned out to be a critical concentration in previous studies [3]. The Aspergillus niger preparation was only noticeably active in the presence of $[\mathrm{BMIM}] \mathrm{Cl}$, but the cellulase derived from Aspergillus sp. showed high activities in the presence of $30 \%(v / v)$ of all tested ILs, and was altogether the most active and IL-tolerant enzyme preparation (Figure 1). For this reason, this extract was chosen for the evaluation of its long term stability. Correspondingly, the extract was co-incubated with the respective ILs $(60 \%(v / v))$ at room temperature, and the cellulolytic activity was measured after up to 63 days, in the presence of $30 \%(v / v)$ IL at $37{ }^{\circ} \mathrm{C}$. During this time the enzyme showed stable activities in the presence of [BMIM]Cl, [BMMIM]Cl, [EMIM] [ATF], and [EMIM] [OTF], after a decrease to about 50\% relative activity in the first days. For example, $17 \mathrm{U} / \mathrm{mg}$ (50\% relative activity) were observed after 63 days in the presence of [EMIM] [OTF] (Figure 2) and $12 \mathrm{U} / \mathrm{mg}$ (29\% relative activity) in the presence of $[\mathrm{BMIM}] \mathrm{Cl}$, an IL that has been shown to dissolve crystalline cellulose. To our knowledge, in comparison with bacterial as well as fungal cellulases, the observed high activities over a long time period represent by far the highest and longest stability of cellulolytic activity in the presence of high IL concentrations that have been described. Reasons for this high activity and stability might be that the cellulase extract of Aspergillus sp. is a mixture of different cellulases that work concertedly. Furthermore it has been shown that IL tolerance can be correlated to thermostability and halotolerance [5]. Interestingly, different Aspergillus species have been shown to be halotolerant [10].

Figure 1. Specific activity of cellulase extracts of $A$. niger, A. sp., T. reesei and T. viride in the presence and absence of $30 \%(v / v)$ IL at $37^{\circ} \mathrm{C}$ after $30 \mathrm{~min}$.

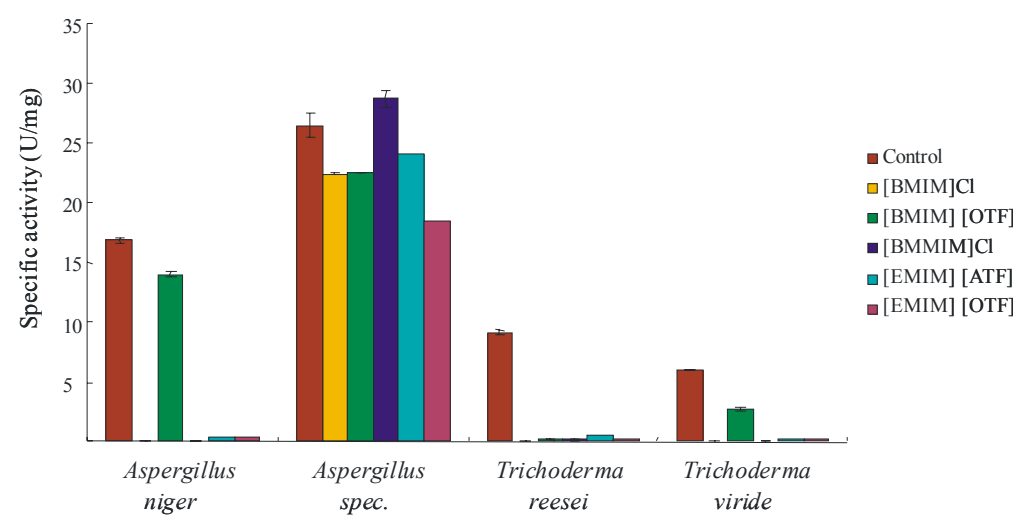


Figure 2. Stability of specific activity of cellulase extracts of A. niger, A. sp., T. reesei and $T$. viride after incubation in the presence and absence of $60 \%(v / v)$ ILs at room temperature; activity was measured in $30 \% \mathrm{IL}(v / v)$ at $37^{\circ} \mathrm{C}$ after $30 \mathrm{~min}$.

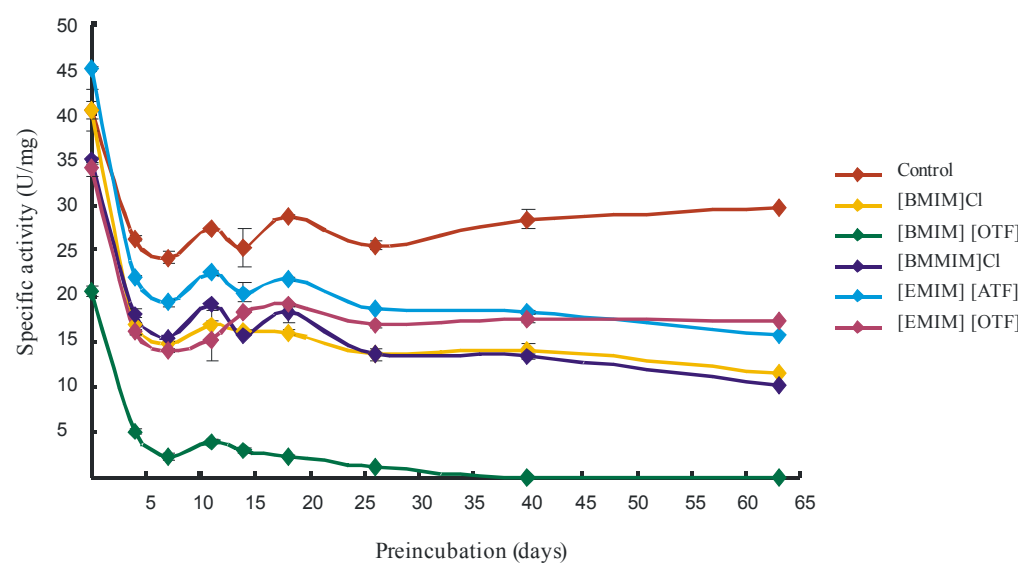

\section{Experimental Section}

In the current study, four commercial cellulase preparations derived from fungi (Aspergillus niger, Sigma-Aldrich; Aspergillus sp., Sigma-Aldrich; Trichoderma reesei, Sigma-Aldrich; Trichoderma viride, Fluka) were tested, as these turned out to be most active in previous work with different Trichoderma, Candida, Aspergillus, and Fusarium extracts (data not shown). The cellulases may contain traces of dextrins, glucose, propylene glycol, and/or sorbitol. The extracts were not further purified and diluted appropriately in TRIS buffer $(50 \mathrm{mM}, \mathrm{pH} 7)$, so that the impurities in the assay would be negligible. The cellulolytic activity and stability was assayed in the presence of the following ILs: 1-butyl-3-methylimidazolium chloride $\quad([\mathrm{BMIM}] \mathrm{Cl}), \quad$ 1-butyl-3-methylimidazolium trifluoromethanesulfonate ([BMIM] [OTF]), 1-butyl-2,3-dimethylimidazolium chloride ([BMMIM]Cl), 1ethyl-3-methylimidazolium trifluoroacetate ([EMIM] [ATF]), and 1-ethyl-3-methylimidazolium trifluoromethanesulfonate ([EMIM] [OTF]). Cellulolytic activity against carboxymethylcellulose (CMC) was measured at $37{ }^{\circ} \mathrm{C}$ with the dinitrosalicylic acid (DNSA) method as described previously [11], using $1 \mu \mathrm{g}$ protein in each $500 \mu \mathrm{L}$ reaction. Units are given as $\mu \mathrm{mol} / \mathrm{min}$.

\section{Conclusions}

The observed high activity and stability of Aspergillus sp. cellulase in the presence of high IL concentrations raises hope that an industrial process employing cellulose for the generation of glucose and subsequent molecules via enzymatic hydrolysis in ionic liquids is possible. Future plans for achieving this goal would be tests on crystalline cellulose and IL treated natural cellulosic substrates like switchgrass or wood. The increase of IL content in the reactions would also be a future prospect.

\section{Acknowledgments}

This work was in part supported by the BMBF-Kompetenznetzwerke Bioraffinerie 2021, the Fachagentur Nachwachsende Rohstoffe and the Merck Company (Darmstadt, Germany). 


\section{Conflict of Interest}

The authors declare no conflict of interest.

\section{References}

1. Heinze, T.; Schwikal, K.; Barthel, S. Ionic liquids as reaction medium in cellulose functionalization. Macromol. Biosci. 2005, 5, 520-525.

2. Swatloski, R.P.; Spear, S.K.; Holbrey, J.D.; Rogers, R.D. Dissolution of cellulose [correction of cellose] with ionic liquids. J. Am. Chem. Soc. 2002, 124, 4974-4975.

3. Pottkämper, J.; Barthen, P.; Ilmberger, N.; Schwaneberg, U.; Schenk, A.; Schulte, M.; Ignatiev, N.; Streit, W.R. Applying metagenomics for the identification of bacterial cellulases that are stable in ionic liquids. Green Chem. 2009, 11, 957-965.

4. Turner, M.B.; Spear, S.K.; Huddleston, J.G.; Holbrey, J.D.; Rogers, R.D. Ionic liquid salt-induced inactivation and unfolding of cellulase from Trichoderma reesei. Green Chem. 2003, 5, 443-447.

5. Ilmberger, N.; Meske, D.; Juergensen, J.; Schulte, M.; Barthen, P.; Rabausch, U.; Angelov, A.; Mientus, M.; Liebl, W.; Schmitz, R.A.; et al. Metagenomic cellulases highly tolerant towards the presence of ionic liquids-linking thermostability and halotolerance. Appl. Microbiol. Biotechnol. 2012, 95, 135-146.

6. Liang, C.; Xue, Y.; Fioroni, M.; Rodriguez-Ropero, F.; Zhou, C.; Schwaneberg, U.; Ma, Y. Cloning and characterization of a thermostable and halo-tolerant endoglucanase from Thermoanaerobacter tengcongensis MB4. Appl. Microbiol. Biotechnol. 2011, 89, 315-325.

7. Beckham, G.T.; Dai, Z.; Matthews, J.F.; Momany, M.; Payne, C.M.; Adney, W.S.; Baker, S.E.; Himmel, M.E. Harnessing glycosylation to improve cellulase activity. Curr. Opin. Biotechnol. 2012, 23, 338-345.

8. Hong, J.; Tamaki, H.; Akiba, S.; Yamamoto, K.; Kumagai, H. Cloning of a gene encoding a highly stable endo-beta-1,4-glucanase from Aspergillus niger and its expression in yeast. J. Biosci. Bioeng. 2001, 92, 434-441.

9. Steen, P.V.D.; Rudd, P.M.; Dwek, R.A.; Opdenakker, G. Concepts and principles of O-linked glycosylation. Crit. Rev. Biochem. Mol. Biol. 1998, 33, 151-208.

10. Zheng, J.; Xu, Z.; Wang, Y.; Hong, K.; Liu, P.; Zhu, W. Cyclic tripeptides from the halotolerant fungus Aspergillus sclerotium PT06-1. J. Nat. Prod. 2010, 73, 1133-1137.

11. Ilmberger, N.; Streit, W.R. Screening for cellulase-encoding clones in metagenomic libraries. Methods Mol. Biol. 2010, 668, 177-188.

(C) 2013 by the authors; licensee MDPI, Basel, Switzerland. This article is an open access article distributed under the terms and conditions of the Creative Commons Attribution license (http://creativecommons.org/licenses/by/3.0/). 